\title{
Bone mineral density of Brazilian girls with juvenile dermatomyositis
}

T.C.M. de Castro ${ }^{1}$, M.T.R.A. Terreri ${ }^{1}$, V.L. Szejnfeld ${ }^{2}$, C. Len ${ }^{1}$, A.S.M. da Fonseca ${ }^{3}$ and M.O.E. Hilário ${ }^{1}$

\author{
'Divisão de Alergia, Imunologia e Reumatologia, Departamento de Pediatria, \\ and ${ }^{2}$ Departamento de Medicina Interna, Escola Paulista de Medicina, \\ Universidade Federal de São Paulo, São Paulo, SP, Brasil \\ ${ }^{3}$ Departamento de Pediatria, Universidade Federal do Rio Grande do Norte, Natal, \\ RN, Brasil
}

\section{Correspondence \\ M.T. Terreri \\ Rua Loefgreen, 2381, Apto. 141 \\ 04040-004 São Paulo, SP \\ Brasil \\ Fax: +55-11-5579-1590 \\ E-mail: terreri@uninet.com.br}

Publication supported by FAPESP.

$\ldots \ldots \ldots \ldots \ldots \ldots$

Received November 18, 2003 Accepted September 20, 2004

\begin{abstract}
We measured bone mineral density (BMD) in girls with juvenile dermatomyositis (JDM) considering multiple factors in order to determine if it could be used as a predictor of reduction in bone mass. A cross-sectional study of lumbar spine BMD (L2-L4) was conducted on 10 girls aged 7-16 years with JDM. A group of 20 age-matched healthy girls was used as control. Lumbar spine BMD was measured by dualenergy X-ray absorptiometry. Weight, height and pubertal Tanner stage were determined in all patients and controls. Duration of disease and mean daily and cumulative steroid doses were calculated for all patients on the basis of their medical charts. JDM activity was determined on the basis of the presence of muscle weakness, cutaneous vasculitis and/or elevation of serum concentration of one or more skeletal muscle enzymes. Seven patients demonstrated osteopenia or osteoporosis. Lumbar BMD was significantly lower in the JDM patients than the age-matched healthy control girls $(0.712$ vs 0.878 , respectively; Student $t$-test, $\mathrm{P}=0.041$ ). No significant correlation between BMD and age, height, Tanner stage, disease duration, corticosteroid use, or disease activity was observed in JDM girls, but a correlation was observed between BMD and weight (Pearson's correlation coefficient, $r=0.802$ ). Patients with JDM may be at risk for a significant reduction in BMD that might contribute to further skeletal fragility. Our results suggest that reduced bone mass in JDM may be related to other intrinsic mechanisms in addition to steroid treatment and some aspects of the disease itself may contribute to this condition.
\end{abstract}

\section{Introduction}

Osteoporosis is a disorder characterized by loss of matrix and bone mineral content and microarchitectural deterioration of bone tissue (1). It used to be primarily an agerelated disorder occurring in postmenopausal women and in the elderly, but more recently
Key words

- Dermatomyositis

- Adolescent girls

- Osteoporosis

- Corticosteroids
- Bone mineral density it has been observed to be associated with diseases such as asthma, rheumatoid arthritis, dermatomyositis, and systemic lupus erythematosus (SLE) (2-6). Previous studies have assessed multiple factors as possible contributors to the reduction in bone mineral density (BMD) in patients with these diseases. However, few studies on BMD have 
been conducted on the pediatric population (7-12). Low BMD in patients with juvenile dermatomyositis (JDM) has been associated with a combination of factors such as disease activity, high doses of corticosteroids, low intake of calcium, delayed pubertal stage, low sunlight exposure, and prolonged immobility. An early diagnosis of patients at risk for bone loss is important for the attenuation and management of this condition, which may lead to a poor outcome of JDM when not adequately treated (1).

\section{Material and Methods}

\section{Patients}

We followed the clinical course of 10 female patients with JDM aged 7 to 16 years. All subjects fulfilled the diagnostic criteria for JDM established by Bohan and Peter in 1975 (13). The findings were compared to those obtained for 20 aged-matched healthy girls selected from the community.

The Ethics Committee of Universidade Federal de São Paulo approved the study protocol and informed consent was obtained from persons responsible for the participants.

Weight $(\mathrm{kg})$ and height $(\mathrm{cm})$ were measured in patients and controls using an anthropometric balance. An experienced pediatrician determined the Tanner stage. Patients were classified into two groups: girls within the G1-G2 Tanner range (group 1) and G3G5 girls (group 2). This division was due to the fact that G3 to G5 patients present higher bone mass (14). Duration of disease in months was considered as the period of time from the first clinical manifestations to the evaluation by bone densitometry. Mean daily steroid dose (mg prednisone $\mathrm{kg}^{-1}$ day $^{-1}$ ) and mean cumulative steroid dose $(\mathrm{g})$ were calculated from the medical records.

The medical history of JDM patients was reviewed and disease activity was defined on the basis of the presence of at least one of the following four criteria: 1) muscle weak- ness of the neck flexors and extensors, shoulder abductors, elbow flexors and extensors, hip flexors, extensors, and abductors, and knee flexors and extensors; 2 ) skin vasculitis (heliotrope discoloration of the upper eyelids, Gottron's papules, and abnormalities of the periungual skin); 3) degree of impairment in ambulation, and 4) elevation of one or more serum concentrations of the skeletal muscle enzymes (aspartate aminotransferase, creatine kinase, aldolase, and lactic dehydrogenase). The presence of calcinosis was reviewed, particularly in the lumbar spine.

\section{Dual-energy X-ray absorptiometry}

BMD at the lumbar spine level (L2-L4) was measured in all subjects by dual-energy $\mathrm{X}$-ray absorptiometry using a LUNAR DPX densitometer (Lunar Radiation Corporation, Madison, WI, USA). This site was chosen because of its pathophysiologic importance for vertebral compression fractures and because a high-quality age-related normative database is available for the pediatric population. Z scores were calculated from the BMD data for comparison with published normative data. The densitometer used in our Unit has a coefficient of variation of $2.0 \%$ at the lumbar spine in children.

Lumbar spine radiography was carried out to exclude calcinosis.

\section{Statistical analysis}

The Student $t$-test was used to compare $\mathrm{BMD}$ of patients and controls. The chi-square test was used to compare BMD of controls and JDM patients with Tanner stage. In the JDM group, Pearson's correlation coefficient was used to detect potential associations between BMD and anthropometric measures, time of disease, and mean daily and cumulative steroid doses. The Student $t$ test was also used to compare the BMD of patients with Tanner stage and disease activ- 
ity. All statistical analyses were performed using the SPSS software version 8.0. A P value of $<0.05$ was considered to be statistically significant.

\section{Results}

The demographic, anthropometric and clinical characteristics of the 10 patients and 20 controls are shown in Table 1. No patient showed calcinosis. Seven patients had disease activity and 3 did not. Mean duration of disease was $3.6 \pm 1.6$ years. Mean daily steroid dose was $0.32 \pm 0.21 \mathrm{mg} \mathrm{kg}^{-1}$ day $^{-1}$ and mean cumulative steroid dose was 15.3 $\pm 8.9 \mathrm{~g}$. All patients with JDM were treated with oral or intravenous corticosteroids and at the time of evaluation all patients were taking this medication except one. The two groups were similar in terms of age, weight and height, with no statistically significant difference between them. In the JDM group, 4 patients were in stage G1-G2 and 6 were in stage G3-G5. In the control group, 8 individuals were in stage G1-G2 and 12 were in stage G3-G5. Pubertal development did not show a statistically significant difference between the two groups.

Seven patients had osteopenia or osteoporosis.

Patients with JDM had significantly reduced BMD in the lumbar spine compared to controls $(P=0.041)$. In the JDM group, we did not observe a significant correlation between BMD and age, height, disease duration, or corticosteroid use, although, a statistically significant correlation was observed between BMD and weight $(r=0.802)$. There were no significant differences in BMD between JDM patients in stages G1-G2 and in stages G3-G5 (0.645 vs $\left.0.757 \mathrm{~g} / \mathrm{cm}^{2}\right)$, or between patients with and without disease activity $\left(0.758\right.$ vs $\left.0.645 \mathrm{~g} / \mathrm{cm}^{2}\right)$. No patients had clinical or vertebral fractures (15).

Statistical analysis only allowed the use of simple tests and multiple regression was not performed.

\section{Discussion}

An important determinant of osteoporosis is the peak bone mass achieved during the second decade of life. Thus, osteopenia and osteoporosis originate in childhood and adolescence (16). Children with rheumatic diseases such as juvenile SLE and JDM develop a diminished bone mass both because of the inflammatory nature of the disease and of the use of steroids to treat the active manifestations of the diseases (10). Because many of these patients are diagnosed and treated during the late prepubertal and early pubertal periods when bone formation is more intense, bone loss might lead to osteopenia and to the risk of osteoporosis during adulthood (10). Few reports are available about BMD in patients with JDM (10). Our results demonstrate that children with JDM present a reduced bone mass at the lumbar spine level compared with healthy children.

Steroids are a mainstay drug therapy in JDM and are a well-recognized cause of osteoporosis in other rheumatic diseases (1723). Differently from other reports, our study showed that in children with JDM there is no significant correlation between bone mass and steroid use, a fact possibly due to the small number of patients included in our study.

Table 1. Demographic, anthropometric, clinical characteristics, and bone mineral density of patients with juvenile dermatomyositis and controls.

\begin{tabular}{lcc}
\hline & JDM patients & Controls \\
\hline Number of subjects & 10 & 20 \\
Age (years) & $11.8 \pm 3.2$ & $12.0 \pm 2.8$ \\
Weight $(\mathrm{kg})$ & $38.9 \pm 19.4$ & $41.2 \pm 11.6$ \\
Height $(\mathrm{cm})$ & $137.5 \pm 17.2$ & $148.5 \pm 14.4$ \\
Tanner stage G1-G2/G3-G5 & $4 / 6$ & $8 / 12$ \\
Time of disease (years) & $3.6 \pm 1.6$ & - \\
Daily steroid doses (mg kg-1 day-1) & $0.32 \pm 0.21$ & - \\
Cumulative steroid doses $(\mathrm{g})$ & $15.3 \pm 8.9$ & - \\
Spine bone mineral density $\left(\mathrm{g} / \mathrm{cm}^{2}\right)$ & $0.712 \pm 0.239 *$ & $0.878 \pm 0.179$
\end{tabular}

Data are reported as means \pm SD. JDM = juvenile dermatomyositis. ${ }^{*} \mathrm{P}<0.05$ compared to controls (Student $t$-test). 
Perez et al. (10) showed a significant bone loss associated with decreased calcium absorption in 12 JDM patients receiving steroid therapy. Falcini et al. (1) observed a reduction in both lumbar spine BMD and calcaneal ultrasound measurements in 53 patients with juvenile rheumatoid arthritis $(\mathrm{N}=29)$, juvenile SLE $(\mathrm{N}=13)$ and JDM (N =11) compared with a control group. All JDM patients were taking corticosteroids.

Our results show that weight was statistically correlated with bone mass in JDM patients. This finding agrees with others showing that weight is the best predictor of bone mass in healthy children $(24,25)$.

The most important increase in lumbar spine BMD was found in pubertal stage 4 for both sexes (14). It is during this stage of puberty that the deceleration of the growth spur occurs and adult levels of sex steroids can be attained (14). In our study, we did not find a significant correlation between bone loss and pubertal stage. However, JDM patients who were in stages G1-G2 presented lower BMD than patients in stages G3-G5. Our results indicate some increment in bone mass as a function of pubertal development even in patients with an important reduction in bone density.

All children with osteopenia or osteoporosis were being treated with calcium and vita$\min \mathrm{D}$.
There are many disease-related variables, like reduced serum osteocalcin levels or elevated serum cytokines, that could play a role in determining the BMD of patients with JDM (26-28). Secondary mechanisms resulting in increased susceptibility to bone loss include female sex, immobility due to muscle weakness and constitutional symptoms like anorexia, the deliberate avoidance of sunlight exposure, gastrointestinal vasculitis impairing calcium and vitamin D absorption, and ovarian failure associated with the disease itself or secondary to cytotoxic therapy $(29,30)$. None of these factors were evaluated in our study and perhaps could explain the reduced bone mass in JDM children. Disease activity and steroid treatment did not correlate with BMD in these patients. The present results suggest that the reduced bone mass observed in these children represents a multifactorial process and some aspects of JDM itself may contribute to this condition.

It is important to emphasize that the small sample size of the present study limited our ability to generalize our findings.

\section{Acknowledgments}

We wish to express our thanks to Prof. Clovis de Araujo Peres and Prof. Fabio Tadeu Montesano for statistical assistance.

\section{References}

1. Falcini F, Bindi G, Ermini M, Galluzzi F, Poggi G, Rossi S, Masi L, Cimaz R \& Brandi ML (2000). Comparison of quantitative calcaneal ultrasound and dual energy X-ray absorptiometry in the evaluation of osteoporotic risk in children with chronic rheumatic diseases. Calcified Tissue International, 67: 19-23.

2. Kalla AA, Fataar AB, Jessop SJ \& Bewerunge $L$ (1993). Loss of trabecular bone mineral density in systemic lupus erythematosus. Arthritis and Rheumatism, 36: 1726-1734.

3. Formiga F, Moga I, Nolla JM, Pac M, Mitjavila F \& Roig-Escofet D (1995). Loss of bone mineral density in premenopausal women with systemic lupus erythematosus. Annals of the Rheumatic Diseases, 54: $274-276$

4. Sinigaglia L, Varenna M, Binelli L, Zucchi F, Ghiringhelli D \& Fantini F (2000). Bone mass in systemic lupus erythematosus. Clinical and Experimental Rheumatology, 18 (Suppl 21): S27-S34.
5. Sambrook PN, Eisman JA, Yeates MG, Pocock NA, Eberl S \& Champion GD (1986). Osteoporosis in rheumatoid arthritis: safety of low dose corticosteroids. Annals of the Rheumatic Diseases, 45: 950-953.

6. Sambrook PN, Cohen ML, Eisman JÁ, Pocock NA, Champion GD \& Yeates MG (1989). Effects of low dose corticosteroids on bone mass in rheumatoid arthritis: a longitudinal study. Annals of the Rheumatic Diseases, 48: 535-538.

7. Pepmueller PH, Cassidy JT, Allen SH \& Hillman LS (1996). Bone mineralization and bone mineral metabolism in children with juvenile rheumatoid arthritis. Arthritis and Rheumatism, 39: 746-757.

8. Pereira RMR, Corrente JE, Chahade WH \& Yoshinari NH (1998). Evaluation by dual X-ray absorptiometry (DXA) of bone mineral density in children with juvenile chronic arthritis. Clinical and Experimental Rheumatology, 16: 495-501. 
9. Brik R, Keidar Z, Schapira D \& Israel O (1998). Bone mineral density and turnover in children with systemic juvenile chronic arthritis. Journal of Rheumatology, 25: 990-992.

10. Perez MD, Abrams AS, Koenning G, Stuff JE, O'Brien KO \& Ellis KJ (1994). Mineral metabolism in children with dermatomyositis. Journal of Rheumatology, 21: 2364-2369.

11. Trapani S, Civinini R, Ermini M, Paci E \& Falcini F (1998). Osteoporosis in juvenile systemic lupus erythematosus: a longitudinal study on the effect of steroids on bone mineral density. Rheumatology International, 18: 45-49.

12. Stewart WA, Acott PD, Salisbury SR \& Lang BA (2003). Bone mineral density in juvenile dermatomyositis. Arthritis and Rheumatism, 48: 2294-2298.

13. Bohan A \& Peter J (1975). Polymyositis and dermatomyositis. New England Journal of Medicine, 292: 344-347.

14. De Schepper J, Derde MP, Van Den Broeck M, Piepsz A \& Jonckheer $\mathrm{MH}$ (1991). Normative data for lumbar spine bone mineral content in children: Influence of age, height, weight and pubertal stage. Journal of Nuclear Medicine, 32: 216-220.

15. Genant HK, Wu CY, van Kuijk C \& Nevitt MC (1993). Vertebral fracture assessment using a semiquantitative technique. Journal of Bone and Mineral Research, 8: 1137-1148.

16. Cassidy JT (1999). Osteopenia and osteoporosis in children. Clinical and Experimental Rheumatology, 17: 245-250.

17. Warady BD, Lindsley CB, Robinson FG \& Lukert BP (1994). Effects of nutritional supplementation on bone mineral status of children with rheumatic diseases receiving corticosteroid therapy. Journal of Rheumatology, 21: 530-535.

18. Dykman TR, Haralson KM, Gluck OS, Murphy WA, Teitelbaum SL, Hahn TJ \& Hahn BH (1984). Effects of oral 1,25-dihydroxyvitamin D and calcium on glucocorticoid-induced osteopenia in patients with rheumatic diseases. Arthritis and Rheumatism, 27: 1336-1343.

19. Dykman TR, Gluck OS, Murphy WA, Hahn TJ \& Hahn BH (1985). Evaluation of factors associated with glucocorticoids-induced osteopenia in patients with rheumatic diseases. Arthritis and Rheumatism, 28: 361-368.

20. Hajiroussou VJ \& Webley M (1984). Prolonged low-dose corticosteroid therapy and osteoporosis in rheumatoid arthritis. Annals of the Rheumatic Diseases, 43: 24-27.

21. Dhillon BV, Davies MC, Hall ML, Round JM, Ell PJ, Jacobs HS,
Snaith ML \& Isenberg DA (1990). Assessment of the effect of oral corticosteroids on bone mineral density in systemic lupus erythematosus: a preliminary study with dual energy X-ray absorptiometry. Annals of the Rheumatic Diseases, 49: 624-626.

22. Pons F, Peris P, Guanabens N, Font J, Huguet M, Espinosa G, Ingelmo M, Munoz-Gomez J \& Setoain J (1995). The effect of systemic lupus erythematosus and long-term steroid therapy on bone mass in premenopausal women. British Journal of Rheumatology, 34: 742-746.

23. Reid IR (1989). Pathogenesis and treatment of steroid osteoporosis. Clinical Endocrinology, 30: 83-103.

24. Bonjour JP, Theintz G, Buchs B, Slosman D \& Rizzoli R (1991). Critical years and stages of puberty for spinal and femoral bone mass accumulation during adolescence. Journal of Clinical Endocrinology and Metabolism, 73: 555-563.

25. Theintz G, Buchs B, Rizzoli R, Slosman D, Clavien H, Sizonenko PC \& Bonjour JP (1992). Longitudinal monitoring of bone mass accumulation in healthy adolescents: evidence for a marked reduction after 16 years of age at the levels of lumbar spine and femoral neck in female subjects. Journal of Clinical Endocrinology and Metabolism, 75: 1060-1065.

26. Reed A, Haugen M, Patchman LM \& Langman CB (1990). Abnormalities in serum osteocalcin values in children with chronic rheumatic diseases. Journal of Pediatrics, 116: 574-580.

27. Grondal G, Gunnarsson I, Ronnelid J, Rogberg S, Klareskog L \& Lundberg I (2000). Cytokine production, serum levels and disease activity in systemic lupus erythematosus. Clinical and Experimental Rheumatology, 18: 565-570.

28. Tanaka Y, Watanabe K, Suzuki M, Saito K, Oda S, Suzuki H, Eto S \& Yamashita U (1989). Spontaneous production of bone-resorbing lymphokines by B cells in patients with systemic lupus erythematosus. Journal of Clinical Immunology, 9: 415-420.

29. Babini SM, Arturi A, Marcos JC, Babini JC, Iniguez AM \& Morteo OG (1988). Laxity and rupture of the patellar tendon in systemic lupus erythematosus. Association with secondary hyperparathyroidism. Journal of Rheumatology, 15: 1162-1165.

30. Wallace DJ (1993). The endocrine system and urogenital tract. In: Wallace DJ \& Hahn BH (Editors), Dubois' Lupus Erythematosus. Lea and Febiger, Philadelphia, PA, USA, 407. 